\title{
Hall Thruster Cluster Operation with a Shared Cathode
}

\author{
Mitchell L. R. Walker* and Alec D. Gallimore \\ University of Michigan, Ann Arbor, Michigan 48109
}

DOI: $10.2514 / 1.23688$

\begin{abstract}
The effects of cluster cathode sharing on the performance of a $2 \times 1$ cluster of 5 - $\mathrm{kW}$ Hall effect thrusters are investigated. The cluster is operated from $1.5-6 \mathrm{~kW}$ over a range of backpressures from $4.7 \times 10^{-4} \mathrm{~Pa} \mathrm{Xe}$ $\left(3.5 \times 10^{-6}\right.$ torr $\left.\mathrm{Xe}\right)$ to $1.2 \times 10^{-3} \mathrm{~Pa} \mathrm{Xe}\left(8.9 \times 10^{-6}\right.$ torr $\left.\mathrm{Xe}\right)$. The cluster thruster elements can share a single cathode without coupling their ionization and acceleration processes over a range of centerline separation distances from $0.3 \mathrm{~m}$ to greater than $2 \mathrm{~m}$. The discharge current of both thrusters remains constant, with the shared cathode mounted above one thruster and with the shared cathode centrally located for all thruster-to-thruster centerline separation distances. These results show that the gas flow of one thruster does not directly affect the performance of the adjacent thruster. In addition, the effects of cathode displacement from the thruster centerline on the performance of a $5-\mathrm{kW}$ Hall effect thruster are investigated. The data show that the cathode-to-ground voltage remains nearly constant for thruster-centerline-to-cathode-centerline spacing greater than $0.4 \mathrm{~m}$. A thrustercenterline-to-cathode separation distance up to $1.3 \mathrm{~m}$ does not negatively affect the performance of the thruster, and reliable restarts are possible at the maximum displacement distance.
\end{abstract}

\section{Introduction}

$\mathbf{T}$ HE combination of high specific impulse, high thrust efficiency, and high thrust density makes the closed-drift Hall thruster (CDT) appealing for a number of Earth-orbit space missions. CDTs can satisfy many of the spacecraft propulsion needs of the U.S. Air Force (USAF) and industrial satellite producers for the next several decades. The USAF has identified the high-power 50-150 kW CDT propulsion system as the baseline approach for a variety of missions [1]. Next-generation communication satellites are becoming both larger and more powerful. Recent satellite designs suggest that electric propulsion (EP) systems will have to double or triple in power from the current $3-5 \mathrm{~kW}$ systems within the next decade to satisfy commercial spacecraft needs. This means that vacuum systems will have to be modified to handle the added propellant flow rates demanded by these higher-power thrusters.

Many national electric propulsion test facilities, although physically large enough to test $50-\mathrm{kW}$ thrusters, possess pumping speeds that are at least an order of magnitude too low to ameliorate facility pressure effects for plume/contamination and life testing. If the tank pressure is too high, the background gas can artificially modify the exhaust plume and alter the operation of the CDT itself [2-4]. The U.S. Air Force Research Laboratory (AFRL), NASA John H. Glenn Research Center (GRC), and laboratories in Europe have recently upgraded their pumping systems in anticipation of higher-powered thrusters. Nevertheless, very few vacuum facilities capable of testing CDTs greater than $100 \mathrm{~kW}$ are expected to be available in the foreseeable future. Thus, modular, high-power CDT propulsion systems will undoubtedly be required for both USAF and NASA missions in the future, to make ground testing feasible.

To address this issue, the USAF has embarked on the concept of clustering to reach its high-power goal (i.e., the use of smaller Hall thrusters in a propulsion array [5]). Clustering allows a single smaller

Received 6 March 2006; revision received 10 September 2006; accepted for publication 20 November 2006. Copyright () 2006 by Mitchell L. R. Walker. Published by the American Institute of Aeronautics and Astronautics, Inc., with permission. Copies of this paper may be made for personal or internal use, on condition that the copier pay the $\$ 10.00$ per-copy fee to the Copyright Clearance Center, Inc., 222 Rosewood Drive, Danvers, MA 01923; include the code 0748-4658/07 \$10.00 in correspondence with the CCC.

*Assistant Professor, College of Engineering, Department of Aerospace Engineering, High-Power Electric Propulsion Laboratory, 449 Guggenheim Building, 270 Ferst Drive. Member AIAA.

Professor, College of Engineering, Department of Aerospace Engineering, Plasmadynamics and Electric Propulsion Laboratory, 3037 FXB Building, 1320 Beal Avenue. Associate Fellow AIAA.
Hall thruster that can be analyzed with ground-based testing in a number of test facilities to be used in the cluster. A cluster of thrusters will have a lower total efficiency and higher dry mass than a monolithic device of equal power. Yet, a cluster provides propulsion system redundancy and the ability to vary the system power while allowing the thrusters in use to operate at their peak efficiency. Clusters also provide the ability to generate torques about the center of mass by simply turning off one or more of the thrusters. Moreover, a cluster is more likely to provide higher performance over a wider range of power than a monolithic engine, given the modular nature of the former.

A limited number of studies have addressed the concept of CDT clustering. Beal [5-9] characterized the basic plume properties, "cross talk" among cluster elements, and cluster sensitivity to cathode placement with a $2 \times 2$ cluster of Busek model BHT-200-X3 Hall thrusters. The European Office of Aerospace Research and Development conducted tests at the Russian Central Research Institute of Machine Building (TSNIIMASH) with a cluster of three D-55 anode-layer Hall thrusters to demonstrate that multiple thrusters can share a single cathode and operate from one common power supply with no noticeable increase in discharge current oscillations and no sign of cross talk between the thrusters for a fixed separation distance $[\underline{10,11]}$.

The work presented here is directed at the development of a Hall thruster cluster test facility centered around the University of Michigan (UM) Large Vacuum Test Facility (LVTF) [ㄱ, $\underline{8}, \underline{12}]$. A $2 \times 1$ cluster of AFRL/UM P5, 5-kW Hall thrusters has been constructed at the UM to facilitate the investigation of high-power Hall thruster operation. This work aims to further understand the feasibility of operating clusters of Hall thrusters on spacecraft. The study investigates the effects of cathode sharing and cathode-tothruster separation over a wide range of separation distances on the operation of a Hall thruster cluster at operating conditions of 300 and $500 \mathrm{~V}$ at 5.25 and $10.46 \mathrm{mg} / \mathrm{s}$. In addition, the effect of cathode displacement on single-thruster performance is measured with a thrust stand.

\section{Experimental Apparatus}

\section{A. Vacuum Facility}

All experiments are conducted in the LVTF, shown schematically in Fig. 1. The cluster is mounted at thruster station 2. The LVTF is a stainless-steel-clad vacuum chamber that has a diameter of $6 \mathrm{~m}$ and a length of $9 \mathrm{~m}$. The LVTF pumping speed is varied by changing the number of cryopumps in operation $[13,14]$. The combined pumping speed of the facility is 500,000 1/s on air and $240,000 \mathrm{l} / \mathrm{s}$ on xenon, with a base pressure of $2 \times 10^{-5} \mathrm{~Pa}$ 


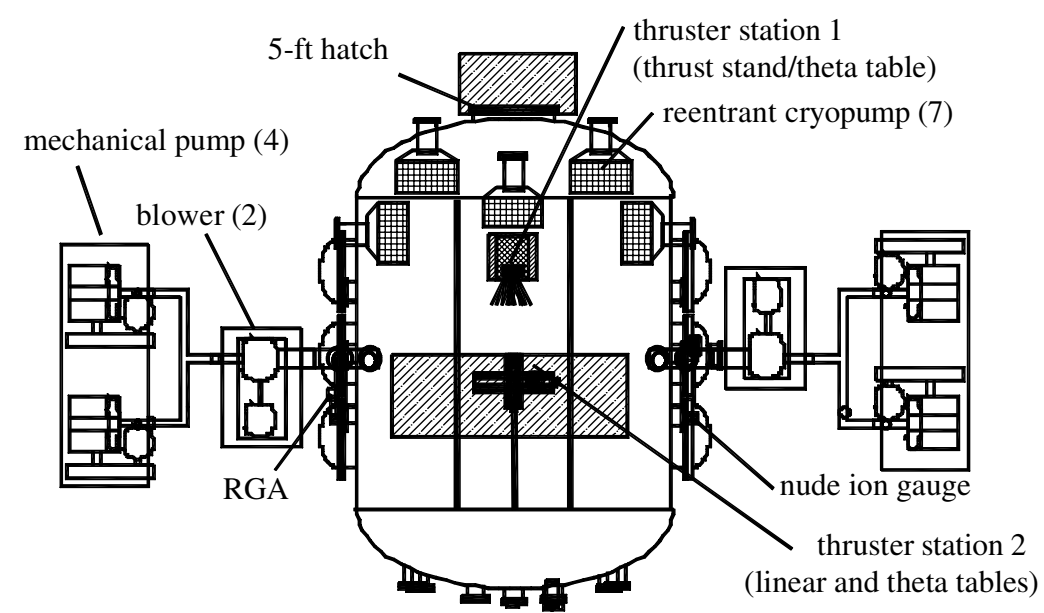

Fig. 1 Diagram of the LVTF (AFRL/UM 2 × 1 5-kW P5 Hall thruster cluster).

$\left(1.5 \times 10^{-7}\right.$ torr $)$. At the average anode flow rates investigated ( 5.25 and $10.46 \mathrm{mg} / \mathrm{s}$, both with a $0.92 \mathrm{mg} / \mathrm{s}$ cathode flow) and at a nominal xenon pumping speed of $240 \mathrm{kl} / \mathrm{s}$, the operating pressures of the LVTF range from $4.7 \times 10^{-4} \mathrm{~Pa} \mathrm{Xe}\left(3.5 \times 10^{-6}\right.$ torr $\left.\mathrm{Xe}\right)$ to $1.2 \times 10^{-3} \mathrm{~Pa} \mathrm{Xe}\left(8.9 \times 10^{-6}\right.$ torr $\left.\mathrm{Xe}\right)$. The change in facility pressure caused by turning off one cathode in the cluster cathodesharing experiments is negligible.

Table 1 shows the LVTF operating pressure for each flow rate at the nominal xenon pumping speeds of $240 \mathrm{kl} / \mathrm{s}$. The operating pressures are adequate for plume and performance measurements [3]. The chamber pressures listed in Table 1 are the indicated pressures from the nude gauge, corrected for xenon using the known base pressure on air and a correction factor of 2.87 for xenon [15]. A previous study shows that the nude gauge reading is the best estimate of the true chamber pressure [16].

Chamber pressure is monitored by a nude ionization gauge, as indicated in [14]. The gauge is a Varian model UHV-24 nude gauge with a Varian UHV SenTorr vacuum gauge controller. The UHV-24 nude gauge is calibrated for air by the manufacturer. Pressure measurements are corrected for xenon using the known base pressure on air and a correction factor of 2.87 for xenon, according to the following equation [15]:

$$
P_{c}=\frac{P_{i}-P_{b}}{2.87}+P_{b}
$$

where $P_{c}$ is the corrected pressure on xenon, $P_{b}$ is the base pressure, and $P_{i}$ is the indicated pressure when xenon is flowing into the vacuum chamber. The ionization gauge measures pressure over the range of $10^{-2} \mathrm{~Pa}\left(10^{-4}\right.$ torr $)$ to $10^{-10} \mathrm{~Pa}\left(10^{-12}\right.$ torr $)$ with an accuracy of $\pm 20 \%$, as reported in [17].

\section{B. Hall Thruster}

All experiments are performed on the AFRL/UM P5 $2 \times 1$ cluster of laboratory-model Hall thrusters. The P5 has a mean diameter of $148 \mathrm{~mm}$, a channel width of $25 \mathrm{~mm}$, a channel depth of $38 \mathrm{~mm}$, and a nominal power rating of $5 \mathrm{~kW}$. Laboratory-model cathodes are located at the 12 o'clock position on each of the thrusters. The cathode orifice is located approximately $30 \mathrm{~mm}$ downstream of the

Table 1 LVTF background pressure for the investigated flow rates at a nominal pumping speed of $240 \mathrm{kl} / \mathrm{s}$ (anode and cathode flow rates have an uncertainty of \pm 0.2 and $\pm 0.02 \mathrm{mg} / \mathrm{s}$, respectively).

\begin{tabular}{lcccc}
\hline \hline Thruster & Anode, mg/s & Cathode, mg/s & $\begin{array}{c}\text { Pressure, } \\
\text { torr Xe }\end{array}$ & $\begin{array}{c}\text { Pressure, } \\
\text { Pa Xe }\end{array}$ \\
\hline Single & 5.25 & 0.92 & $3.5 \mathrm{E}-06$ & $4.7 \mathrm{E}-04$ \\
Single & 10.46 & 0.92 & $5.3 \mathrm{E}-06$ & $7.1 \mathrm{E}-04$ \\
Cluster & 10.5 & 1.84 & $5.4 \mathrm{E}-06$ & $7.2 \mathrm{E}-04$ \\
Cluster & 20.92 & 1.84 & $8.9 \mathrm{E}-06$ & $1.2 \mathrm{E}-03$ \\
\hline \hline
\end{tabular}

outer front pole piece. The cathode flow rate is set at $0.92 \mathrm{mg} / \mathrm{s}$ for all cases investigated. Although the original P5 discharge channel is machined from M-grade boron nitride, the discharge channels of the cluster elements use the less expensive HP-grade boron nitride. No appreciable change in thruster operating characteristics or performance was observed due to the change in discharge channel material. The P5 thrusters used in this study are dedicated to cluster research and have nearly identical numbers of operational hours. A more detailed description of the P5 can be found in [18].

Each of the P5 Hall thrusters is powered by a separate set of power supplies and operates from its own cathode, as shown in Fig. 2. The thruster electrical connections enter the chamber through two separate feedthrough ports. Each thruster discharge supply is connected to a filter consisting of a $1.3-\Omega$ resistance in series with the discharge current and a $95-\mu \mathrm{F}$ capacitor in parallel. The filter provides isolation of the discharge power supply from the discharge oscillations of the plasma and insures that any oscillations are not a product of feedback between the power supplies and plasma. Discharge current oscillations are measured with a F.W. Bell IHA-25 Hall effect current sensor connected to a Tektronix TDS 3034B

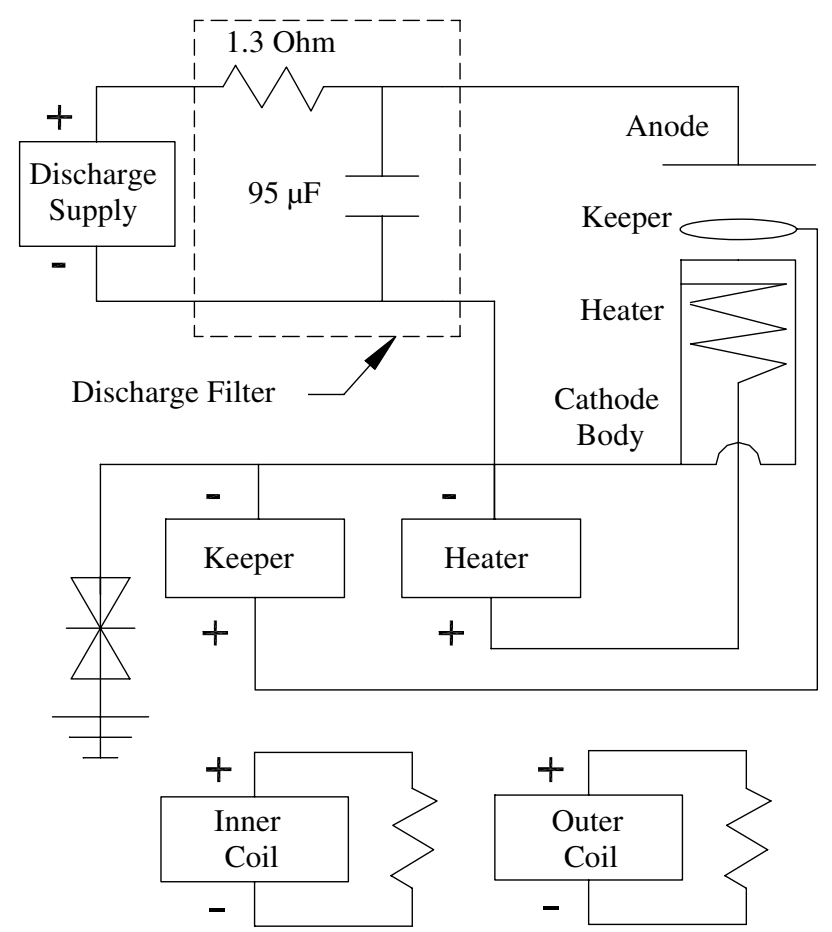

Fig. 2 Electrical schematic of power electronics used to run the P5 Hall thruster. 
oscilloscope. A more detailed description of the discharge current oscillations can be found in [19]. High-purity (99.9995\% pure) xenon propellant is supplied to the Hall thrusters from compressed gas bottles through stainless-steel feed lines. MKS 1179JA mass flow controllers meter the anode and cathode propellant flows. The flow controllers are calibrated with a custom apparatus that measures gas pressure and temperature as a function of time in an evacuated chamber of known volume. The mass flow controllers have an accuracy of $\pm 1 \%$ full scale. The thrusters use independent mass flow controllers for all experiments.

\section{Thrust Stand}

Thrust is measured with a null-type, inverted-pendulum thrust stand of NASA GRC design [1]. The springs of the stand are made with extra stiffness to accommodate the weight of high-power thrusters. The null-type thrust stand holds the thruster at a set position at all thrust levels, which reduces error in the thrust by eliminating changes in the elevation of the thrust vector. The designer reports the error of the thrust stand to be $\pm 1 \%$ of the full-scale calibration. The uncertainty of the thrust measurements in this experiment, determined by examination of the hysteresis and drift of the zero offset and calibration slope variation, is $\pm 1 \mathrm{mN}$.

In situ thruster/thrust-stand leveling is performed with a remotely controlled, geared dc motor coupled to a jackscrew. A remotely controlled, geared-dc-motor-driven pulley system is employed to provide in situ thrust-stand calibration by loading and offloading small weights to simulate thrust before and after each test point. A linear curve fit of null-coil voltage versus calibrated weight (thrust) is then obtained and used for performance measurements. Soon after the thruster is turned off, a posttest calibration is performed. Magnetic tares are measured by passing current through each set of thruster magnet coils and are found to be negligible. Cold flow tares due to cathode-only flow without a discharge are also found to be negligible. This last result is expected, because the cathode centerlines are inclined approximately $45 \mathrm{deg}$ below the horizontal. Anode flow tares are not required, because the anode flow is closed throughout the calibration.

The thrust stand is actively cooled with a VWR International 1172 refrigerated recirculating chiller to maintain thermal equilibrium at high-power Hall thruster operating conditions. The thrust-stand cooling consists of two and one-half parallel cooling circuits that travel through the structure and outer radiation shroud. The shroud cooling water temperature is monitored by the chiller and never increases by more than $5^{\circ} \mathrm{C}$ over the thruster-off condition.

\section{Cluster Spacing}

One of the most important criteria for Hall thruster clustering is the spacing of the array elements. To minimize structural mass and the physical envelope of the cluster, elements of the cluster should be as close as possible without adversely affecting their performance. In large part, the magnetic field inside the Hall thruster channel governs the performance of the Hall thruster [20]. A previous study uses cluster elements spaced $40 \mathrm{~cm}$ apart (centerline to centerline), to ensure that the magnetic field within the discharge chamber and the external radial field are unaffected by the adjacent element of the cluster array at the maximum magnetic field strength operating condition of the monolithic thruster [21]. This paper investigates cluster operation for spacing (centerline to centerline) both less than and greater than $40 \mathrm{~cm}$.

The electric fields within the plume plasma may also affect the performance of clustered thrusters. The magnitude of the plasma potential in the plume is not large enough to create an electric field sufficient to cause a substantial deviation in the trajectory of highspeed ions created in the discharge channel. Therefore, plume interaction should not be large enough to affect the performance of the individual elements. However, weak electric fields in the plume may alter the plume by changing the trajectories of the slow chargeexchange (CEX) ions [7]. The study in [7] is performed at a pressure of $4.8 \times 10^{-4} \mathrm{~Pa} \mathrm{Xe}\left(3.6 \times 10^{-6}\right.$ torr $\left.\mathrm{Xe}\right)$. This effect is not investigated in this study, because it is expected to have a very minor influence on cluster performance.

\section{Results and Discussion}

Thruster discharge current $I_{D}$ and cathode-to-ground voltage $V_{\mathrm{cg}}$ are monitored as a function of separation distance (centerline to centerline) for each configuration. The magnetic field remains constant for each operating condition at all separation distances. These measurements are performed for thruster operating conditions of 300 and $500 \mathrm{~V}$ at anode flow rates of 5.25 and $10.46 \mathrm{mg} / \mathrm{s}$. The data show two distinct characteristics that are not a direct result of clustering. First, discontinuities in the steady-state operation of the thrusters are caused by elevated facility backpressure due to the cluster propellant flow rates. The discontinuities are characterized by abrupt changes in the flow operating mode. The discontinuities are most evident at the $500 \mathrm{~V}, 10.46 \mathrm{mg} / \mathrm{s}$ operating condition. The $10.46 \mathrm{mg} / \mathrm{s}$ anode flow rate results in elevated backpressure, which increases the number of electron-neutral collisions in the discharge channel. The collisions enhance the electron mobility to the anode, which leads to changes in the discharge current. The discontinuities cause disruptions in the discharge current and the cathode-to-ground potential trends. Second, when operating at equivalent discharge voltage and anode flow rate, the cluster elements have different discharge currents and cathode-to-ground potentials. The differences in the magnitude of the discharge current and cathode-to-ground voltage between the thruster elements are due primarily to manufacturing and assembly tolerances.

The data show several important features of clustering that are critical for spacecraft design considerations. The next four subsections present the results of the cluster cathode-sharing and cluster displacement investigations. Each subsection presents the physical configuration, results of the data analysis, and discussion of their significance.

\section{A. Separate Cathodes}

The P5-A and P5-B are operated through electrically independent circuits in which each has its own cathode and power supply. Figure 3 a shows a schematic of this configuration, which serves as a baseline for the cluster operation from a shared cathode. The cluster elements are operated with their cathodes mounted at the 12 o'clock position. The initial thruster centerline separation is $30.5 \mathrm{~cm}$, which results in a minimum separation distance of $1 \mathrm{~cm}$ between the Hall thruster magnet poles. The poles are not allowed to touch, to avoid any unforeseen complications with the electrical circuits. The initial thruster separation distance (centerline to centerline) is $30.5 \mathrm{~cm}$ and the measurements are taken in 4-cm increments, out to a maximum separation distance of $140.5 \mathrm{~cm}$.

Figures $\underline{4}$ and $\underline{5}$ present the discharge current as a function of separation distance for the 5.25 and $10.46 \mathrm{mg} / \mathrm{s}$ operation conditions, respectively. The figures show that the discharge current remains nearly constant, with increasing distance between the cluster element centerlines. Figure 6 shows that the discharge current is not steady at the $500 \mathrm{~V}, 46 \mathrm{mg} / \mathrm{s}$ operation condition. As mentioned earlier, the variation in the discharge current is a result of the elevated facility backpressure, not the separation distance.

Figures $\underline{6}$ and 7 present the cathode-to-ground voltage for the 5.25 and $10.46 \overline{\mathrm{mg}} / \mathrm{s}$ operating conditions, respectively. Figure $\underline{6}$ shows that the cathode-to-ground voltage is constant, with separation for all $5.25 \mathrm{mg} / \mathrm{s}$ anode flow rate conditions. Figure 7 shows that at the $300 \mathrm{~V}, 10.46 \mathrm{mg} / \mathrm{s}$ operating condition, the cathode-to-ground voltage is nearly constant. However, the cathode-to-ground voltage varies with the unsteady discharge current at $500 \mathrm{~V}, 10.46 \mathrm{mg} / \mathrm{s}$. As the separation distance changes, the adjacent magnetic field strength decreases and the local plasma density decreases, but data from the separate-cathode configuration show that these changes have no effect on cathode-to-ground voltage or on discharge current. This means that the actual changes in magnetic field and plasma density caused by an adjacent thruster are negligible. 


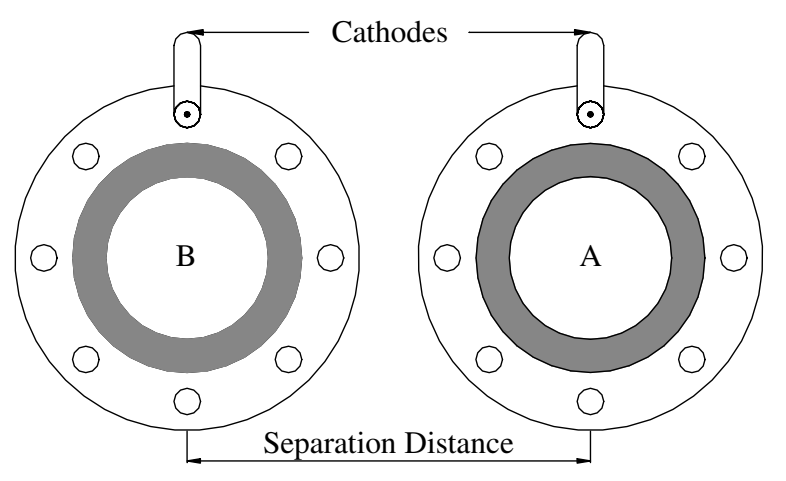

a)

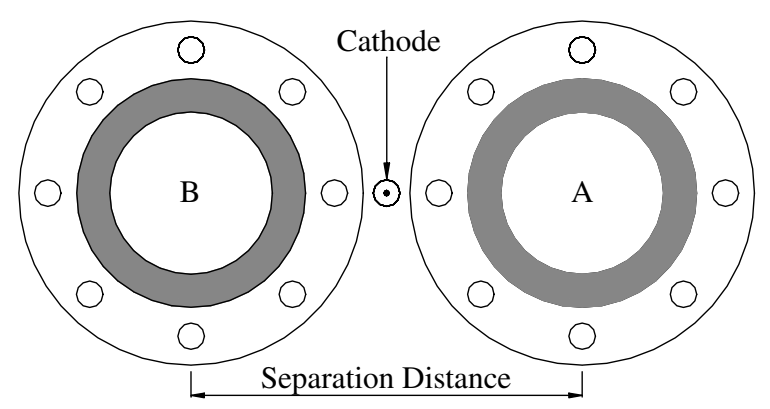

b)

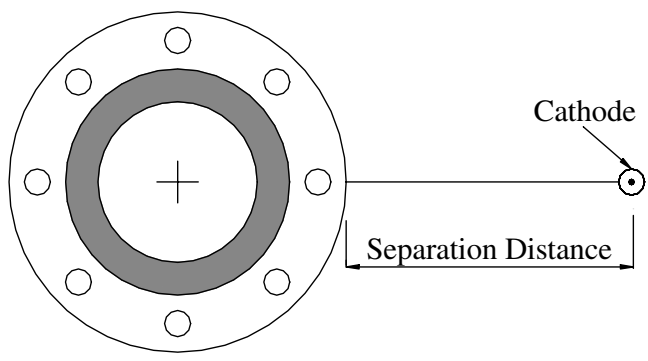

c)

Fig. 3 Cluster diagrams of a) separate cathodes, b) sharing a single cathode, and c) cathode displacement setup (cathode is initially $20 \mathrm{~cm}$ from the thruster centerline).

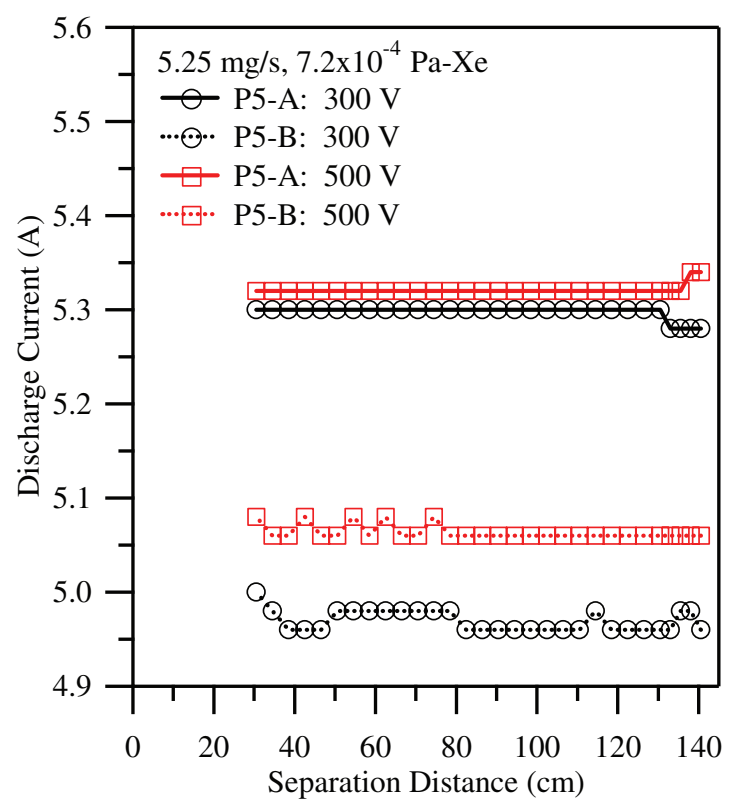

Fig. 4 Separate cathodes; discharge current as a function of thruster centerline distance for anode flow rates of $5.25 \mathrm{mg} / \mathrm{s}$ at a backpressure of $7.2 \times 10^{-4} \mathrm{~Pa} \mathrm{Xe}\left(5.4 \times 10^{-6}\right.$ torr $\left.\mathrm{Xe}\right)$.

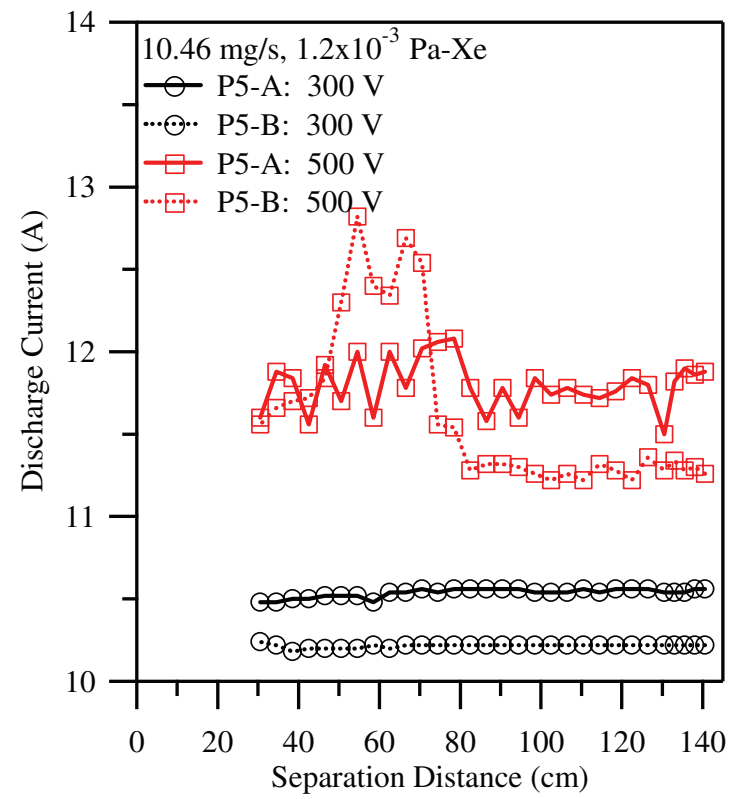

Fig. 5 Separate cathodes; discharge current as a function of thruster centerline distance for anode flow rates of $10.46 \mathrm{mg} / \mathrm{s}$ at a backpressure of $1.2 \times 10^{-3} \mathrm{~Pa} \mathrm{Xe}\left(8.9 \times 10^{-6}\right.$ torr $\left.\mathrm{Xe}\right)$.

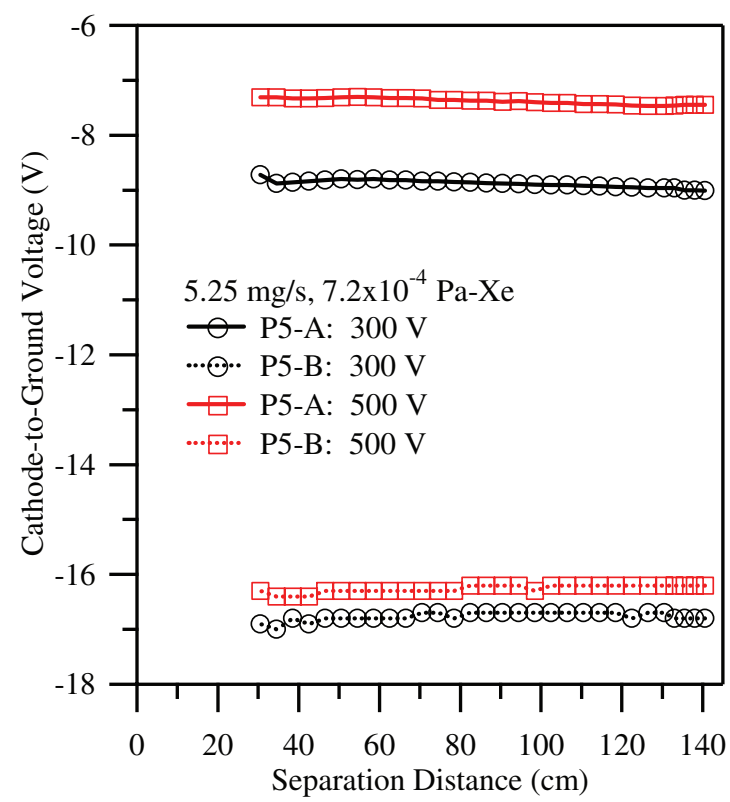

Fig. 6 Separate cathodes; cathode-to-ground voltage as a function of thruster centerline distance for an anode flow rate of $5.25 \mathrm{mg} / \mathrm{s}$ at a backpressure of $7.2 \times 10^{-4} \mathrm{~Pa} \mathrm{Xe}\left(5.4 \times 10^{-6}\right.$ torr Xe).

Prior cluster work suggests that neutral gas from one thruster element can be ingested by the adjacent thruster, thus affecting its performance [21]. The separate-cathode configuration allows investigation of this phenomenon. Although P5-A and P5-B operate from independent cathodes, one of the thrusters and its cathode are turned off, but the anode and cathode flow remain constant. The discharge current and cathode-to-ground voltage of the adjacent thruster is monitored over the range of centerline-to-centerline separation distances. Both the discharge current and cathode-toground voltage remain constant for all separation distances investigated $(30.5-140.5 \mathrm{~cm})$, with cold and hot flow exhausted from the adjacent thruster. The measurements show that the discharge current is not a function of the distance between the thruster centerlines. Thus, there is no measurable change in performance due to ingestion, as previous work suggests [21]. Instead, the increase in thrust reported in [7] with a low-power Hall cluster may be caused by plume electric fields focusing the CEX ions downstream. 


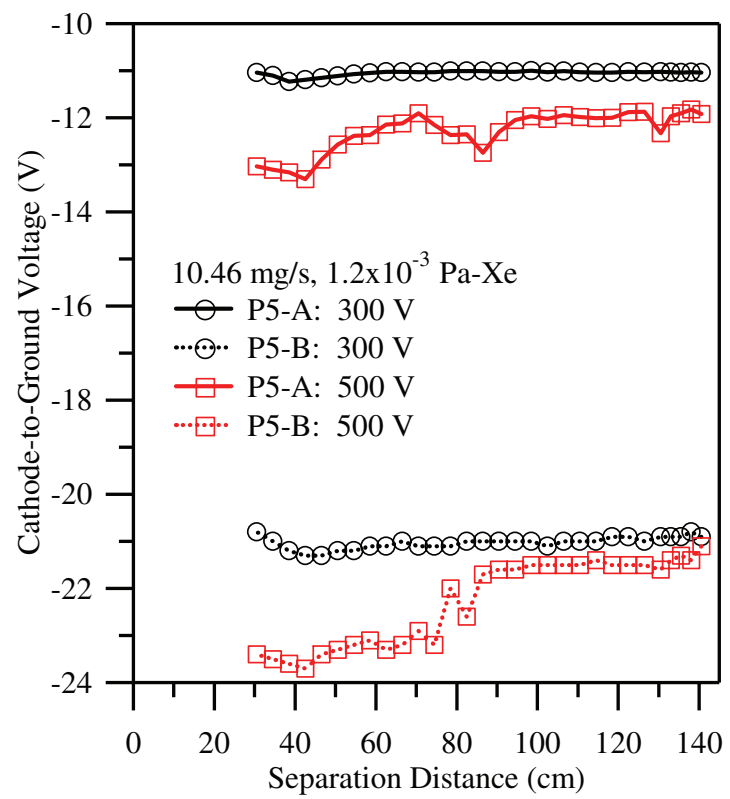

Fig. 7 Separate cathodes; cathode-to-ground voltage as a function of thruster centerline distance for an anode flow rate of $10.46 \mathrm{mg} / \mathrm{s}$ at a backpressure of $1.2 \times 10^{-3} \mathrm{~Pa} \mathrm{Xe}\left(8.9 \times 10^{-6}\right.$ torr Xe $)$.

\section{B. Sharing the Cathode of an Adjacent Thruster}

For this portion of the investigation, the P5-A and P5-B are operated from the cathode of a single thruster. Figure 3 a shows a schematic of this configuration, with the cathodes mounted at the 12 o'clock position. Figure $\underline{8}$ shows a diagram of the electrical circuit used to operate the cluster elements from the shared cathode. The centerline-to-centerline separation distances are identical to the separate cathode experiment described earlier. No gas flows through the nonoperating cathode. Sharing cathode A or cathode B does not change the characteristics of the discharge current or the cathode-toground voltage curves. Thus, only the results for sharing cathode A are presented.

Figures $\underline{9}$ and 10 present the discharge current as a function of separation distance, sharing cathode A for the 5.25 and $10.46 \mathrm{mg} / \mathrm{s}$ operation conditions, respectively. Figure 9 shows that the discharge current remains nearly constant at the $5.25 \mathrm{mg} / \mathrm{s}$ anode flow rate for all separation distances. Figure 10 shows discontinuities in the discharge current at the $10.46 \mathrm{mg} / \mathrm{s}$ anode flow rate, which are due to backpressure effects.

Figure 11 presents the cathode-to-ground voltage as a function of separation distance when sharing cathode A for the $5.25 \mathrm{mg} / \mathrm{s}$ operation conditions. The $10.46 \mathrm{mg} / \mathrm{s}$ operating condition showed an identical trend, and so the results are not presented here. Figure 11 shows that the cathode-to-ground voltage decreases by less than $1 \overline{\mathrm{V}}$ for a centerline-to-centerline separation distance up to $1.785 \mathrm{~m}$ at the $5.25 \mathrm{mg} / \mathrm{s}$ operating condition. This behavior is expected, because the plasma density and magnetic field topology near the cathode,

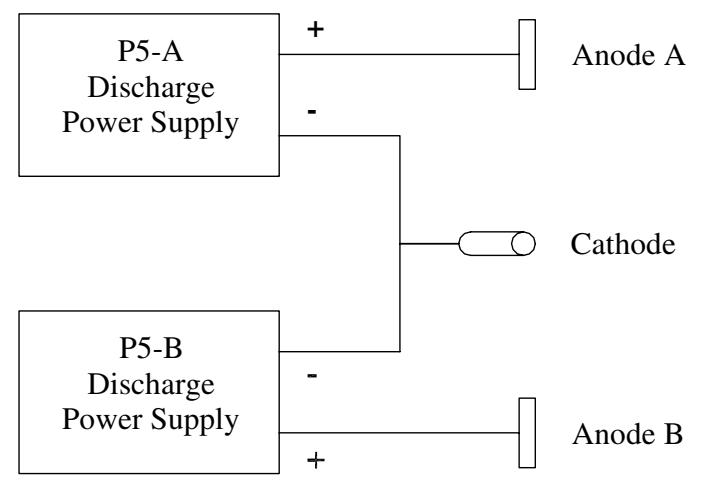

Fig. 8 Diagram of the shared-cathode circuit.

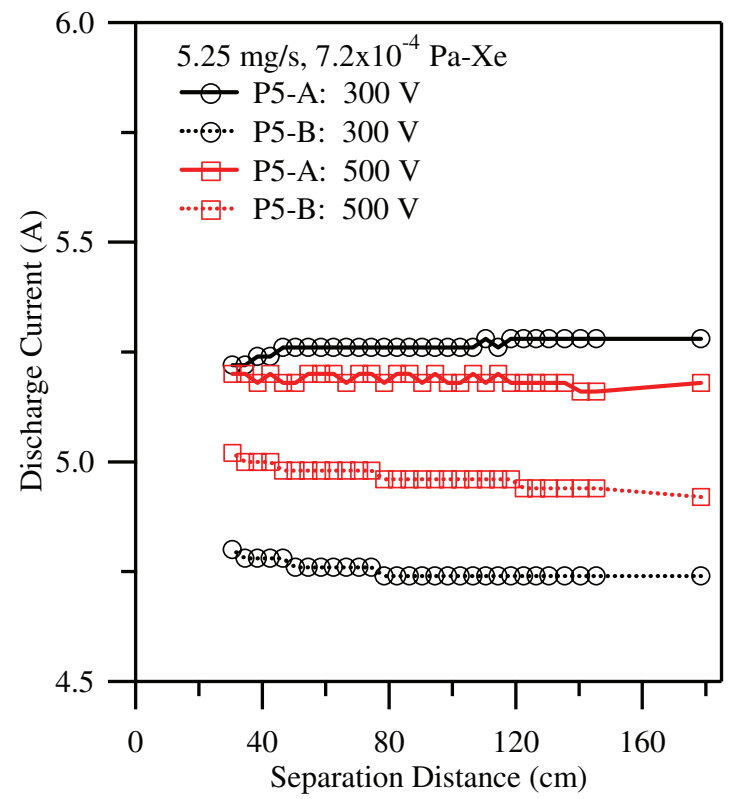

Fig. 9 Sharing cathode A; discharge current as a function of thruster centerline distance $5.25 \mathrm{mg} / \mathrm{s}$ at a backpressure of $7.2 \times 10^{-4} \mathrm{~Pa} \mathrm{Xe}$ $\left(5.4 \times 10^{-6}\right.$ torr Xe).

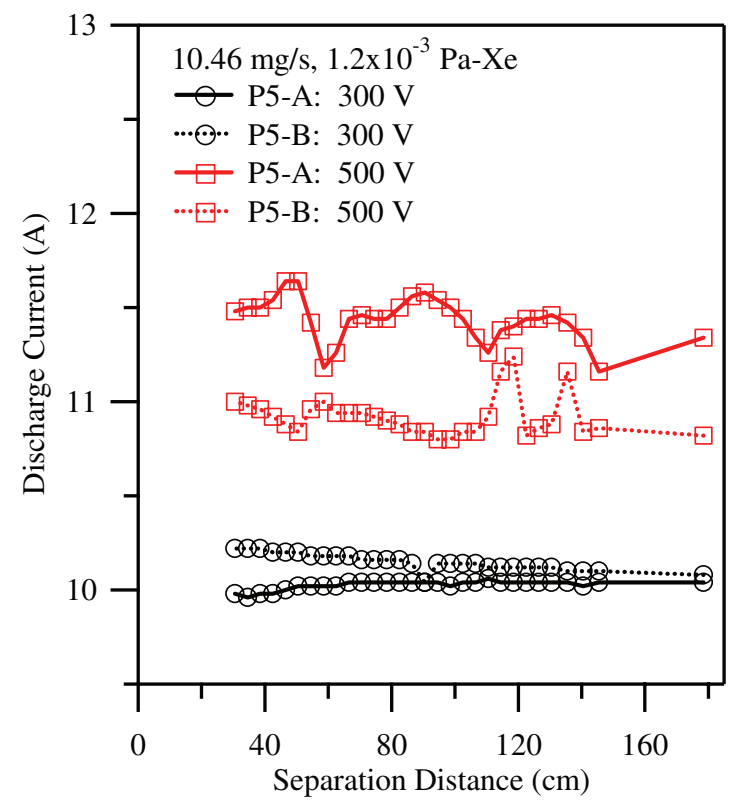

Fig. 10 Sharing cathode $A$; discharge current as a function of thruster centerline distance $10.46 \mathrm{mg} / \mathrm{s}$ at a backpressure of $1.2 \times 10^{-3} \mathrm{~Pa} \mathrm{Xe}$ $\left(8.9 \times 10^{-6}\right.$ torr Xe).

which govern charged-particle transport to and from the cathode, remain constant as the centerline-to-centerline distances varies. Overall, the results show that no deleterious effects result from the cluster sharing the cathode of one of the thrusters.

\section{Sharing a Centered Cathode}

For this portion of the investigation, the P5-A and P5-B are operated from the centered cathode B. Figure $3 \mathrm{~b}$ shows a diagram of the physical configuration, and Fig. $\underline{8}$ shows the electrical circuit through which the thrusters share the cathode. The effect of cluster centerline-to-centerline separation distance is investigated by varying the distance between the thrusters and monitoring the discharge current and cathode-to-ground voltage. The initial centerline-to-centerline separation distance is $0.39 \mathrm{~m}$ and the measurements are taken in $5-\mathrm{cm}$ increments, out to a maximum separation distance of $1.97 \mathrm{~m}$. 


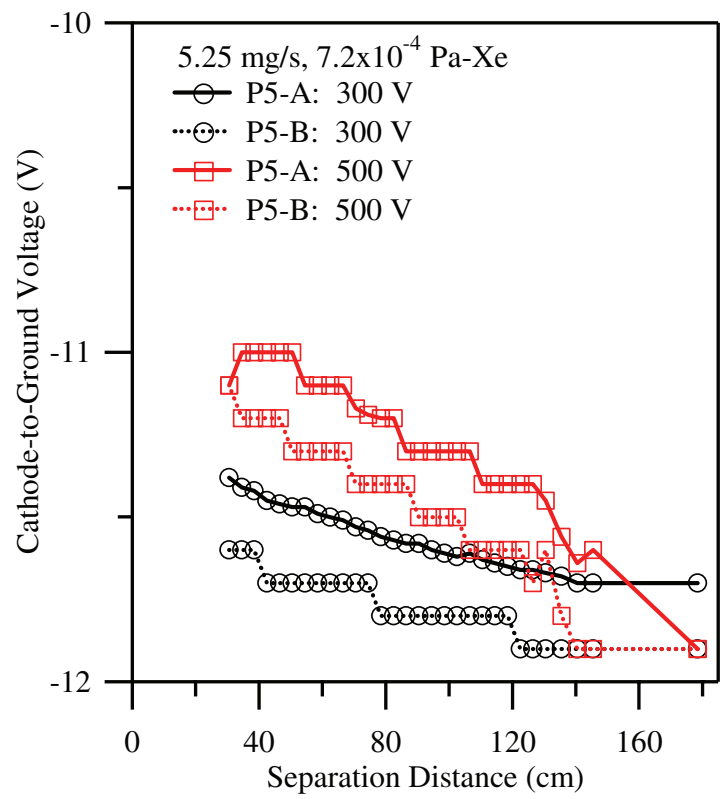

Fig. 11 Sharing cathode A; cathode-to-ground voltage as a function of thruster centerline distance $5.25 \mathrm{mg} / \mathrm{s}$ at a backpressure of $7.2 \times$ $10^{-4} \mathrm{~Pa} \mathrm{Xe}\left(5.4 \times 10^{-6}\right.$ torr Xe $)$.

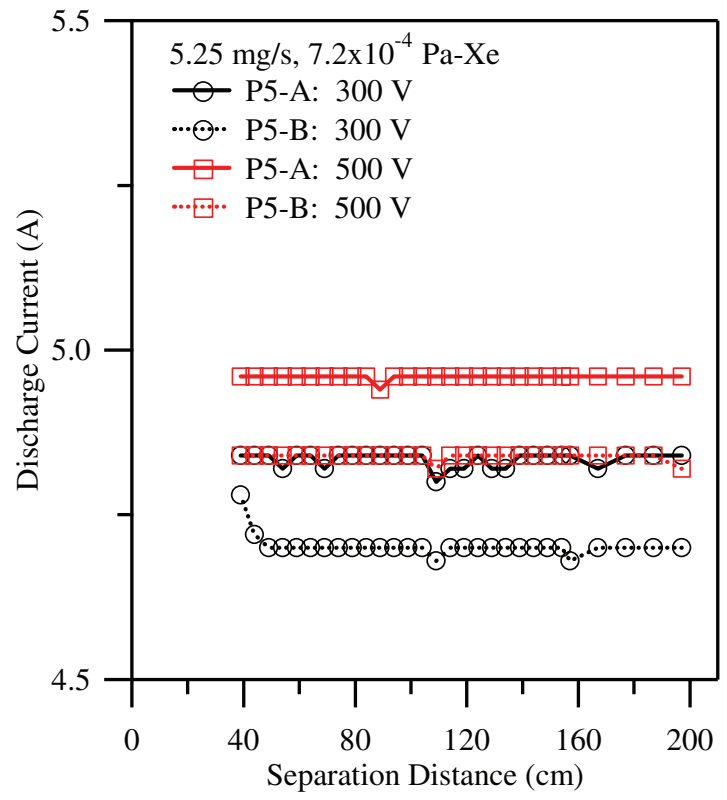

Fig. 12 Sharing a centered cathode; discharge current as a function of thruster centerline distance at an anode flow rate of $5.25 \mathrm{mg} / \mathrm{s}$ at a backpressure of $7.2 \times 10^{-4} \mathrm{~Pa} \mathrm{Xe}\left(5.4 \times 10^{-6}\right.$ torr $\left.\mathrm{Xe}\right)$.

Figures 12 and 13 show that the discharge current of each cluster element is nearly constant as a function of centerline separation distance for the 5.25 and $10.46 \mathrm{mg} / \mathrm{s}$ operation conditions, respectively. There is a slight variation in the discharge current at the $10.46 \mathrm{mg} / \mathrm{s}$ anode flow rate, due to the elevated facility backpressure, which is discussed in a previous section.

Figures 14 and 15 show that as the distance between the centered cathode and the thruster centerline increases, the magnitude of the cathode-to-ground voltage also increases for the 5.25 and $10.46 \mathrm{mg} / \mathrm{s}$ operation conditions, respectively. This trend persists until the cathode-to-thruster centerline distance reaches $0.7 \mathrm{~m}$. Because the setup is bilaterally symmetric, the thruster centerline-to-centerline spacing is thus $1.4 \mathrm{~m}$. The magnitude of the cathode-to-ground voltage increases by approximately $8 \mathrm{~V}$ and plateaus between 24 and $28 \mathrm{~V}$ below ground. Analyses of the data show that this behavior is not characterized by a simple power law, but is well-approximated by a fourth-order polynomial. Unfortunately, this fit does not shed light

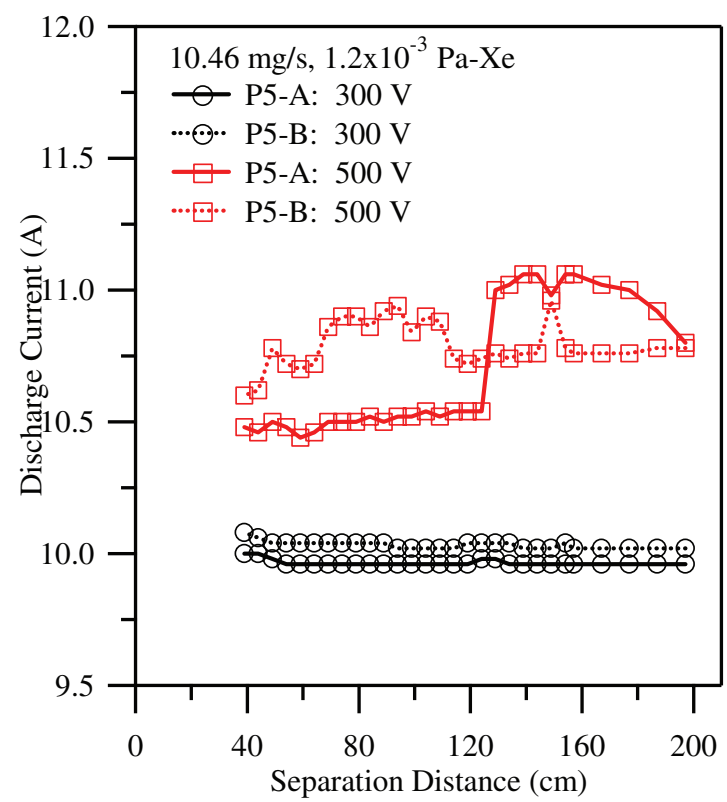

Fig. 13 Sharing a centered cathode; discharge current as a function of thruster centerline distance at an anode flow rate of $10.46 \mathrm{mg} / \mathrm{s}$ at a backpressure of $1.2 \times 10^{-3} \mathrm{~Pa} \mathrm{Xe}\left(8.9 \times 10^{-6}\right.$ torr $\left.\mathrm{Xe}\right)$.

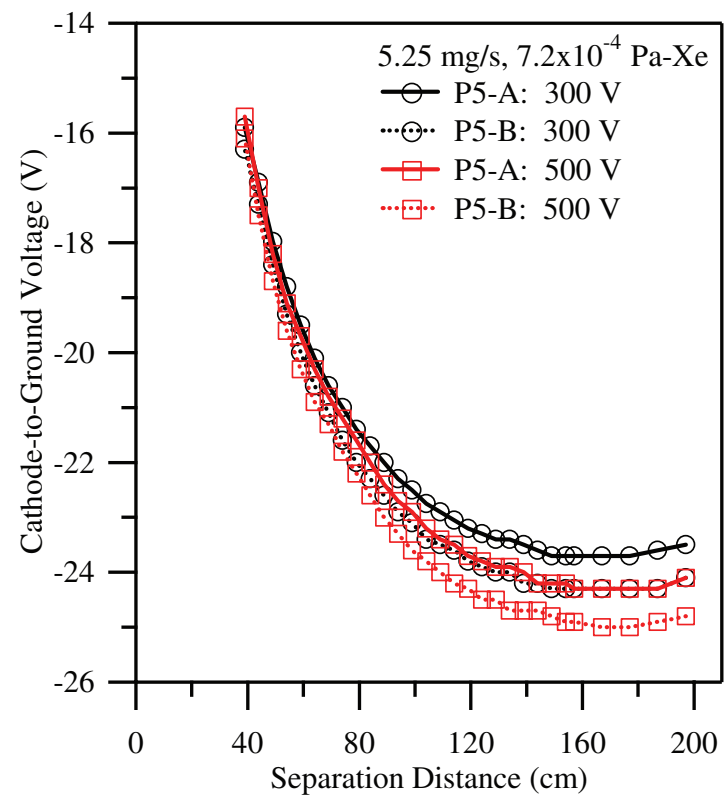

Fig. 14 Sharing a centered cathode; cathode-to-ground voltage as a function of thruster centerline distance at an anode flow rate of $5.25 \mathrm{mg} / \mathrm{s}$ at a backpressure of $7.2 \times 10^{-4} \mathrm{~Pa} \mathrm{Xe}\left(5.4 \times 10^{-6}\right.$ torr Xe $)$.

on the physical processes that govern the change in cathode-toground voltage with cathode-to-thruster centerline distance.

The cathode coupling voltage may change with separation distance, because the plasma density and magnetic field strength near the cathode decrease as the centerline-to-centerline distance increases. A previous study shows that the magnetic field is negligible $20 \mathrm{~cm}$ from the thruster centerline, yet the cathode-toground voltage does not asymptote until the cathode is $70 \mathrm{~cm}$ from thruster centerline [21]. Thus, the magnetic field should not affect the cathode-to-ground voltage. To understand the change in cathode-toground voltage with cathode-to-thruster centerline distance, we must characterize the plasma between the thruster and the cathode.

The thruster operation parameters do not appear to affect the change in cathode-to-ground voltage with separation distance. The data show that the anode flow rate has little effect on the cathode-toground trend. The 300- and 500-V discharge voltages result in no more than a $2-\mathrm{V}$ difference in cathode-to-ground voltage. The in- 


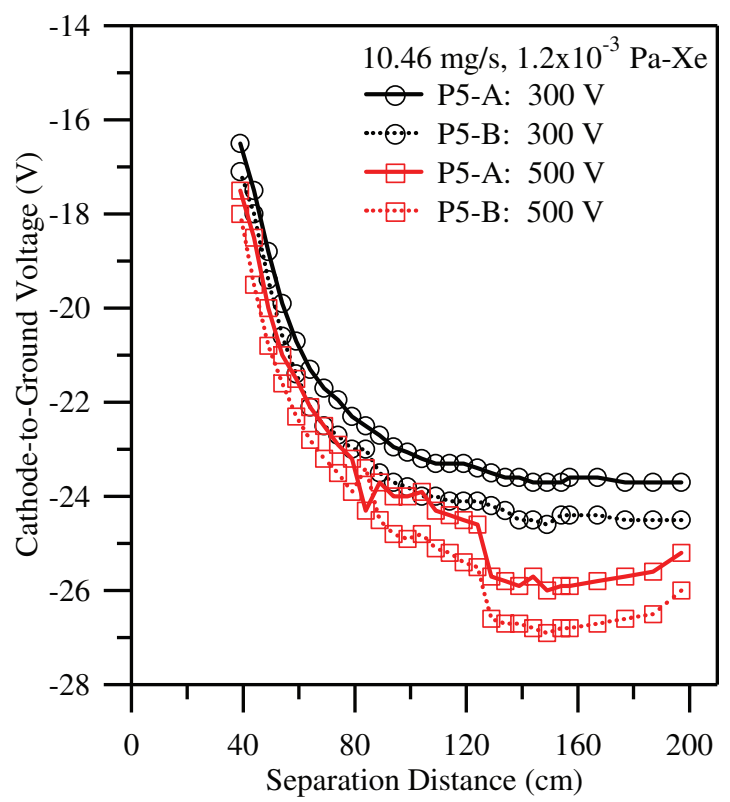

Fig. 15 Sharing a centered cathode; cathode-to-ground voltage as a function of thruster centerline distance at an anode flow rate of $10.46 \mathrm{mg} / \mathrm{s}$ at a backpressure of $1.2 \times 10^{-3} \mathrm{~Pa} \mathrm{Xe}\left(8.9 \times 10^{-6}\right.$ torr $\left.\mathrm{Xe}\right)$.

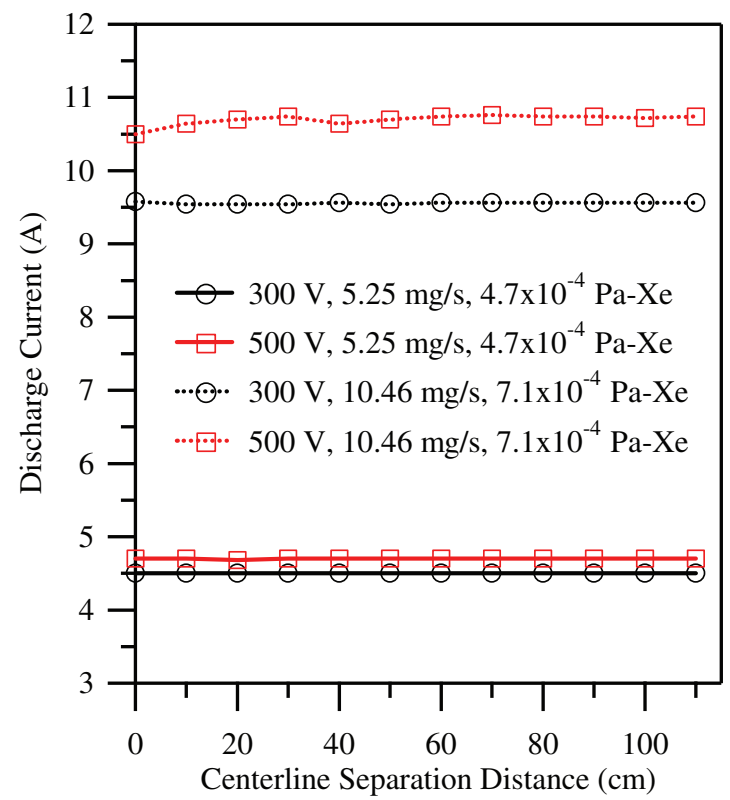

Fig. 16 Discharge current versus front pole-to-cathode centerline separation distance for a nominal pumping speed of $240 \mathrm{kl} / \mathrm{s}$.

crease in the magnitude of the cathode-to-ground voltage reduces the exit velocity of the beam ions, but the difference is negligible in comparison to the discharge voltage ( $4 \%$ for $300 \mathrm{~V}$ and $2.4 \%$ for $500 \mathrm{~V}$ ).

\section{Operation from a Displaced Cathode}

For this experiment, the P5-B is operated from its own cathode. However, the effect of cathode separation distance is investigated by varying the distance between the cathode and thruster centerline distance. Figure 3 shows a diagram of the cathode displacement from the thruster setup. The cathode centerline is initially $20 \mathrm{~cm}$ from the thruster centerline. The axial table moves the cathode to a distance of $1.3 \mathrm{~m}$ from the thruster centerline. The thrust, discharge current, and cathode-to-ground voltage are measured in $10-\mathrm{cm}$ increments at each of the four operating conditions investigated.

Figures 16-19 present the results of the cathode displacement investigation. Figure 16 shows traces of the thruster discharge current

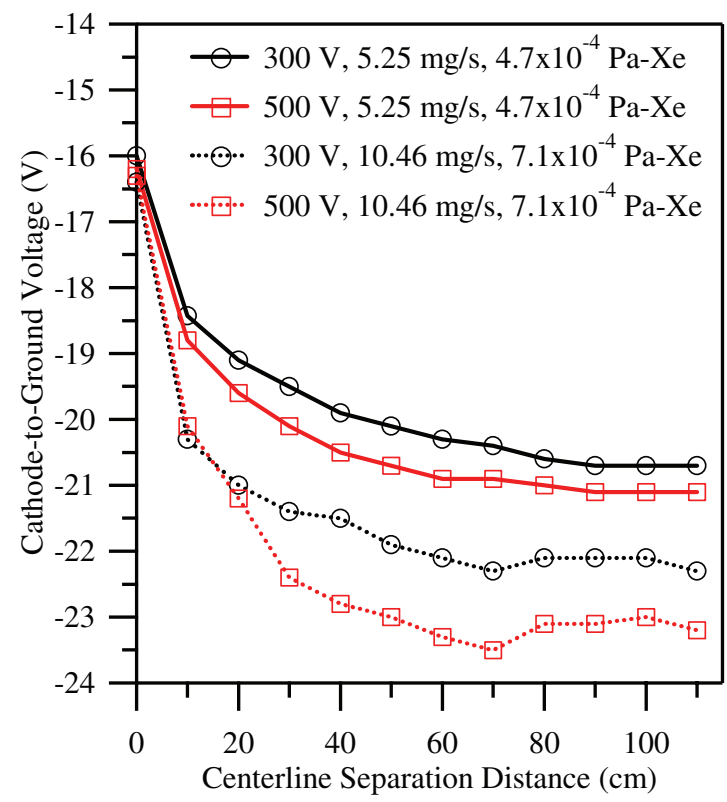

Fig. 17 Cathode-to-ground floating voltage versus front pole-tocathode centerline separation distance for a nominal pumping speed of $240 \mathrm{kl} / \mathrm{s}$.

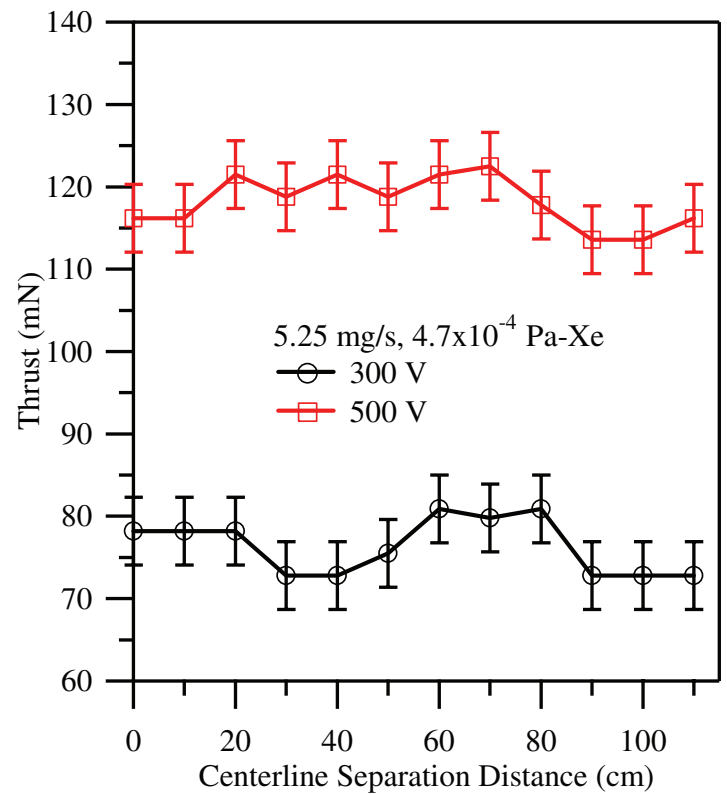

Fig. 18 Thrust versus front pole-to-cathode centerline separation distance for the $5.25 \mathrm{mg} / \mathrm{s}$ anode flow rate at a nominal pumping speed of $240 \mathrm{kl} / \mathrm{s}$.

and the cathode-to-ground voltage as a function of the separation distance between the thruster and cathode centerlines. Figure 16 shows that the discharge current remains constant as a function of cathode displacement distance for all operating conditions. Figure 17 shows traces of the cathode-to-ground voltage as a function of the separation distance between the thruster and cathode centerlines. Figure 17 shows that the cathode-to-ground voltage increases in magnitude as the cathode is displaced from the thruster. The magnitude of the cathode-to-ground voltage for each operating condition asymptotes to its maximum value at a cathode separation distance of approximately $70 \mathrm{~cm}$. As with the cluster sharing the centered cathode, we must characterize the plasma between the thruster and the cathode to understand this behavior.

Figures 18 and 19 show traces of the thrust as a function of the separation distance between the thruster and cathode centerlines. In addition, Figs. 18 and 19 show that the thrust for each condition does not change as the cathode is displaced from the thruster 


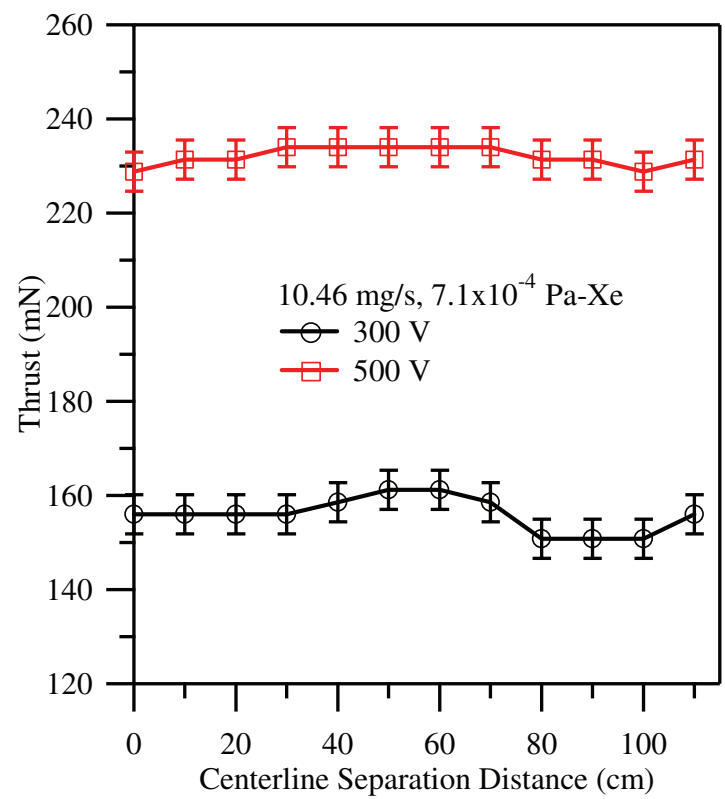

Fig. 19 Thrust versus front pole-to-cathode centerline separation distance for the $10.46 \mathrm{mg} / \mathrm{s}$ anode flow rate at a nominal pumping speed of $240 \mathrm{kl} / \mathrm{s}$.

centerline. There is some drift in the thrust measurements over the range of cathode displacement. This drift is because the translating axial table causes a deflection in the chamber floor grating to which the thrust stand is attached. The resulting thrust-stand tilt, along with the vibration caused by the stepper motor rotation, creates an error in the thrust measurements. Nonetheless, the drift in the thrust measurements is nearly within typical error bounds for the thrust stand. Thus, cathode displacement from the thruster does not appear to cause a change in the thrust produced by the Hall thruster.

It is clear that a Hall thruster operates efficiently from a cathode that is displaced from its usual position on the thruster. However, to position cathodes on spacecraft that are significantly displaced from the thruster centerline, the thruster must be able to start with the cathode in the displaced position. This study verifies that the P5 Hall thruster can be reliably restarted at the $300 \mathrm{~V}, 5.25 \mathrm{mg} / \mathrm{s}$ operating condition, at an operating pressure of $3.5 \times 10^{-6}$ torr Xe, with a cathode displaced up to $1.3 \mathrm{~m}$ away from the thruster centerline.

The only difference between the displaced cathode start procedure and a standard Hall thruster configuration start procedure is when the magnets are turned on. The first step in the displaced cathode starting procedure is to run the cathode on the keeper. Next, one sets the anode mass flow rate to the amount required for the operating condition. Then one sets the anode discharge voltage to that of the operating condition. The plasma breaks down in less than $2 \mathrm{~s}$ from the time that the anode voltage is reached. Finally, one increases the magnetic coil current to the level required for the given operating condition.

The size of the axial positioning table limits the cathode centerline to thruster centerline separation distance to $1.3 \mathrm{~m}$. It may be possible to start and operate the thruster at greater cathode separation distances, because the data show no trends that would prevent further separation.

\section{Conclusions}

The study characterizes the operation of clustered thrusters for various separation distances and cathode-sharing configurations. This investigation establishes that the gas of one thruster element is not ingested into the adjacent thruster at station 2 of the LVTF. It also shows that varying the separation distance between the thruster centerlines from $0.3 \mathrm{~m}$ (with the poles nearly touching) to $1.405 \mathrm{~m}$ causes no negative effect on the performance of the individual thrusters. The cathode-sharing study shows that the cluster elements can operate in several cathode-sharing configurations at thruster centerline separation distances up to $1.97 \mathrm{~m}$. The only change in thruster performance occurs when the cathode is not immersed in the magnetic field of one of the thrusters. As the cathode leaves the magnet field, the magnitude of the cathode-to-ground voltage increases by approximately $8 \mathrm{~V}$; the cathode-to-ground voltage stabilizes for cathode-to-thruster centerline distances of $70 \mathrm{~cm}$ and greater. In addition, reliable restarts for cathode-to-thruster centerline distances of $1.3 \mathrm{~m}$ are verified. This knowledge opens the design envelope of EP-propelled spacecraft and allows propulsion system redundancy by placing cathodes in convenient locations. This knowledge is of great importance to spacecraft designers implementing electric propulsion systems.

\section{Acknowledgments}

The research contained herein was sponsored by the U.S. Air Force Office of Scientific Research. (Mitat Birkan is the contract monitor.) M. L. R. Walker was supported by the Michigan Space Grant Consortium and the National Science Foundation. The authors are greatly appreciative of this support. The authors would like to thank James Haas at the U.S. Air Force Research Laboratory (AFRL) for supplying the Plasmadynamics and Electric Propulsion Laboratory (PEPL) with the cluster elements, Terry Larrow for fabricating the hardware used in this study, Sergi Khartov at the Moscow State Aviation Institute (MAI) for use of the $\mathrm{LaB}_{6}$ cathode design, and the departmental technical staff and other graduate students at PEPL for help in maintaining the facilities.

\section{References}

[1] Jankovsky, R. S., Jacobson, D., and Manzella, D. H., "50 kW Class Krypton Hall Thruster Performance," 39th Joint Propulsion Conference and Exhibit, Huntsville, AL, AIAA Paper 2003-4550, 2003.

[2] Semenkin, A., Kim, V., Gorshkov, O., and Jankovsky, R. S., "Development of Electric Propulsion Standards-Current Status and Further Activity," 27th International Electric Propulsion Conference, Pasadena, CA, International Electric Propulsion Conference, Paper 2001-070, 2001.

[3] Randolph, T., Kim, V., Kaufman, H., Kozubsky, K., Zhurin, V. V., and Day, M., "Facility Effects on Stationary Plasma Thruster Testing," 23rd International Electric Propulsion Conference, Seattle, WA, International Electric Propulsion Conference, Paper 93-093, 1993.

[4] King, L. B., and Gallimore, A. D., "Ionic and Neutral Particle Transport Property Measurements in the Plume of an SPT-100," 32nd Joint Propulsion Conference, Lake Buena Vista, FL, AIAA Paper 96-2712, 1996.

[5] Beal, B. E., and Gallimore, A. D., "The Effects of Clustering Multiple Hall Thrusters on Plasma Plume Properties," 39th Joint Propulsion Conference and Exhibit, Huntsville, AL, AIAA Paper 2003-5155, 2003.

[6] Beal, B. E., "Clustering of Hall Effect Thrusters for High-Power Electric Propulsion Applications," Ph.D. Thesis, Department of Aerospace Engineering, Univ. of Michigan, Ann Arbor, MI, 2003.

[7] Beal, B. E., and Gallimore, A. D., "Energy Analysis of a Hall Thruster Cluster," 28th International Electric Propulsion Conference, Toulouse, France, International Electric Propulsion Conference, Paper 03-0035, 2003.

[8] Beal, B. E., Gallimore, A. D., and Hargus, W., Jr., "Preliminary Plume characterization of a Low-Power Hall Thruster Cluster," 38th Joint Propulsion Conference and Exhibit, Indianapolis, IN, AIAA Paper 2002-4251, July 7-10, 2002.

[9] Beal, B. E., Gallimore, A. D., Haas, J. M., and Hargus, W. A., "Plasma Properties in the Plume of a Hall Thruster Cluster," Journal of Propulsion and Power, Vol. 20, No. 6, 2004, pp. 985-991.

[10] Zakharenkov, L. E., Semenkin, A. V., Urchenko, N. A., Tverdokhlebov, S. O., Garkusha, V. I., Bebedev, T. V., Podkolsin, S. N., and Fife, J. M., "Study of Multi Thruster Assembly Operation," 28th International Electric Propulsion Conference, Toulouse, France, International Electric Propulsion Conference, Paper 2003-0311, 2003.

[11] Teverdokhlebov, S. O., Semenkin, A. V., Baranov, V. I., Zakharenkov, L. E., and Soldukihin, A. E., "Consideration of Cluster Design Approach for High Power Hall Propulsion," 41st Aerospace Sciences Meeting and Exhibit, Reno, NV, AIAA Paper 2003-0494, 2003.

[12] Hargus, W. A., Jr., and Reed, G., "The Air Force Clustered Hall Thruster Program," 38th Joint Propulsion Conference and Exhibit, 
Indianapolis, IN, AIAA Paper 2002-3678, 2002.

[13] Peterson, P. Y., Gallimore, A. D., and Haas, J. M., "An Experimental Investigation of the Internal Magnetic Field Topography of an Operating Hall Thruster," Physics of Plasmas, Vol. 9, No. 10, 2002, pp. 4354-4362.

[14] Walker, M. L. R., and Gallimore, A. D., "Neutral Density Map of Hall Thruster Plume Expansion in a Vacuum Chamber," Review of Scientific Instruments, Vol. 76, May 2005, p. 8.

[15] Dushman, S., Scientific Foundations of Vacuum Technique, Wiley, New York, 1958.

[16] Walker, M. L. R., Gallimore, A. D., Cai, C., and Boyd, I. D., "Pressure Map of a Facility as a Function of Flow Rate to Study Facility Effects," 38th Joint Propulsion Conference and Exhibit, Indianapolis, IN, AIAA Paper 2002-3815, 2002.

[17] "Vacuum Measurement," Product Catalog Varian, Inc. Vacuum Technologies, Palo Alto, CA, 2003; also available at http://www. varianinc.com/cgi-bin/nav?products/vacuum/measure/gauges\&cid= JPLHPIHFO.
[18] Haas, J. M., Gulczinski III, F. S., Gallimore, A. D., Spanjers, G. G., and Spores, R. A., "Performance Characteristics of a $5 \mathrm{~kW}$ Laboratory Hall Thruster," 34th Joint Propulsion Conference and Exhibit, Cleveland, OH, AIAA Paper 98-3503, 1998.

[19] Walker, M. L. R., "Effects of Facility Backpressure on the Performance and Plume of a Hall Thruster," Ph.D. Thesis, Department of Aerospace Engineering, Univ. of Michigan, Ann Arbor, MI, 2005.

[20] Hofer, R. R., and Gallimore, A. D., "Recent Results from Internal and Very-Near-Field Plasma Diagnostics of a High Specific Impulse Hall Thruster," 28th International Electric Propulsion Conference, Toulouse, France, International Electric Propulsion Conference, Paper 2003-037, 2003.

[21] Walker, M. L. R., and Gallimore, A. D., "Performance Characteristics of a Cluster of $5 \mathrm{~kW}$ Laboratory Hall Thrusters," 40th Joint Propulsion Conference, Fort Lauderdale, FL, AIAA Paper 2004-3767, 2004.

E. Choueiri Associate Editor 